\title{
Oral Streptococci Biofilm Formation on Different Implant Surface Topographies
}

\author{
Pedro Paulo Cardoso Pita, ${ }^{1}$ José Augusto Rodrigues, ${ }^{1,2}$ Claudia Ota-Tsuzuki, ${ }^{1}$ \\ Tatiane Ferreira Miato, ${ }^{1}$ Elton G. Zenobio, ${ }^{3}$ Gabriela Giro, ${ }^{1}$ \\ Luciene C. Figueiredo, ${ }^{1}$ Cristiane Gonçalves, ${ }^{1}$ Sergio A. Gehrke, ${ }^{4}$ \\ Alessandra Cassoni, ${ }^{1}$ and Jamil Awad Shibli ${ }^{1}$ \\ ${ }^{1}$ Department of Periodontology and Oral Implantology, Dental Research Division, Guarulhos University, \\ Praça Tereza Cristina 229, 07023-070 Guarulhos, SP, Brazil \\ ${ }^{2}$ Department of Operative Dentistry, Dental Research Division, Guarulhos University, Praça Tereza Cristina 229, \\ 07023-070 Guarulhos, SP, Brazil \\ ${ }^{3}$ Department of Oral Implantology, PUC Minas, Avenida Dom Cabral 500, Prédio 46, Coração Eucarístico, \\ 30535-901 Belo Horizonte, MG, Brazil \\ ${ }^{4}$ Biotecnos-Tecnologia e Ciência Ltda, Rua Dr. Bozano, 571 Centro, 97015-001 Santa Maria, RS, Brazil \\ Correspondence should be addressed to José Augusto Rodrigues; gutojar@yahoo.com
}

Received 7 September 2014; Revised 4 November 2014; Accepted 4 November 2014

Academic Editor: David M. Dohan Ehrenfest

Copyright (C) 2015 Pedro Paulo Cardoso Pita et al. This is an open access article distributed under the Creative Commons Attribution License, which permits unrestricted use, distribution, and reproduction in any medium, provided the original work is properly cited.

\begin{abstract}
The establishment of the subgingival microbiota is dependent on successive colonization of the implant surface by bacterial species. Different implant surface topographies could influence the bacterial adsorption and therefore jeopardize the implant survival. This study evaluated the biofilm formation capacity of five oral streptococci species on two titanium surface topographies. In vitro biofilm formation was induced on 30 titanium discs divided in two groups: sandblasted acid-etched (SAE- $n=15)$ and as-machined (M$n=15)$ surface. The specimens were immersed in sterilized whole human unstimulated saliva and then in fresh bacterial culture with five oral streptococci species: Streptococcus sanguinis, Streptococcus salivarius, Streptococcus mutans, Streptococcus sobrinus, and Streptococcus cricetus. The specimens were fixed and stained and the adsorbed dye was measured. Surface characterization was performed by atomic force and scanning electron microscopy. Surface and microbiologic data were analyzed by Student's $t$-test and two-way ANOVA, respectively $(P<0.05)$. S. cricetus, $S$. mutans, and $S$. sobrinus exhibited higher biofilm formation and no differences were observed between surfaces analyzed within each species $(P>0.05)$. S. sanguinis exhibited similar behavior to form biofilm on both implant surface topographies, while S. salivarius showed the lowest ability to form biofilm. It was concluded that biofilm formation on titanium surfaces depends on surface topography and species involved.
\end{abstract}

\section{Introduction}

Establishment of the dental subgingival microbiota is dependent on successive colonization of the tooth surface by several bacterial species [1]. Each of these bacterial species appears to facilitate enamel surface colonization by the next wave of bacterial settlers, resulting in the establishment of an anaerobic Gram-negative microbiota [2]. So far, it is believed that a similar pattern of the same colonization process may occur on the titanium implant surfaces [3-5].
However, the different implant surface topographies could influence the bacterial adsorption [6-8]. Physical and chemical factors may affect the attachment of biofilms to hard surfaces. The surface roughness at micrometer level can increase the surface area and hence increase the bacterial colonization. Roughness also provides protection from shear forces and increases the difficulty of cleaning methods. Furthermore, Kolenbrander et al. [2] have shown that supragingival plaque formation, after initial bacterial colonization, was faster on a rough surface. The roughness 
of different dental implant surfaces can work like grooves for initial periodontal pathogen adhesion $[6,9,10]$.

The oral streptococci are members of the indigenous microbiota mainly in the supragingival environment [11] and species of mutans group such as Streptococcus mutans, Streptococcus sobrinus, and Streptococcus cricetus were related to individuals with teeth because they are able to adhere to nonshedding surfaces, with $S$. mutans being the most prevalent species in humans [12]. Other species such as Streptococcus sanguinis and Streptococcus salivarius are commonly found in healthy periodontal individuals and the latter is related to mucosal surfaces; besides it can contribute to the coaggregation of pathogenic bacteria, such as Porphyromonas gingivalis. Thus the oral streptococci are considered the pioneer colonizers and might participate in the process, which can lead to implant failure on the long term [6].

Therefore, the aim of this in vitro study was to verify the ability of five oral streptococci species to form biofilm on two different titanium surface topographies.

\section{Material and Methods}

2.1. Implant Surface Topography. Thirty discs ( $5 \mathrm{~mm}$ diameter and $3 \mathrm{~mm}$ thickness) made of grade- 4 titanium (Implacil De Bortoli, Sao Paulo, SP, Brazil) were prepared with 2 surface topographies: as-machined $(\mathrm{M})$ and sandblasted acid-etched (SAE) surfaces. The titanium discs with sandblasted acidetched surface were blasted with $50-100 \mu \mathrm{m} \mathrm{TiO}_{2}$ particles. After sandblasting, the specimens were ultrasonically cleaned with an alkaline solution, washed in distilled water, and pickled with maleic acid.

2.2. Implant Surface Characteristics. The samples were first checked for chemical composition with XPS/ESCA (X-ray photoelectron spectroscopy/electron spectroscopy for chemical analysis), and no significant pollution was detected [13]. The topographies at the microscale were then visualized using routine scanning electron microscopy (SEM) control. At the nanoscale, the SEM confirmed that both surface types were nanosmooth, following the current definition $[13,14]$. The sole difference between these 2 tested implant types was therefore the specific surface microtopography.

Atomic force microscopy (AFM, PicoSPM I plus 2100 PicoScan Controller, in contact mode) was used for the surface topography analysis, in contact mode. The AFM scanned areas of $60 \mu \mathrm{m} \times 60 \mu \mathrm{m}$ of each specimen. The measured parameters, such as the arithmetic average of all profile point absolute values $(\mathrm{Ra})$, the root-mean-square of all point values ( $\mathrm{Rq}$ ), and the average absolute height values of the five highest peaks and the depths of the five deepest valleys $(\mathrm{Rz})$, were measured for each group. Representative images of the surfaces of each group of specimens were also taken by scanning electronic microscopy.

2.3. Strains. Streptococcus sanguinis (ATCC 10556), Streptococcus salivarius (ATCC 7073), Streptococcus mutans (ATCC 25175) and Streptococcus sobrinus (ATCC 33478), and
Streptococcus cricetus (ATCC 19642) were used in this study in biofilm formation.

2.4. Saliva Coating of the Specimens. Unstimulated saliva from 6 healthy nonsmoker and systemic healthy donors was collected for one hour per day, for seven days. Then the saliva samples were sterilized and frozen at $-20^{\circ} \mathrm{C}$ until a total of $500 \mathrm{~mL}$ was collected per donor. All donors signed the informed consent. Subsequently, the saliva samples were pooled and centrifuged $\left(30 \mathrm{~min} ; 4^{\circ} \mathrm{C} ; 27,000 \times \mathrm{g}\right)$. The supernatant was pasteurized $\left(60^{\circ} \mathrm{C}, 30 \mathrm{~min}\right)$ to inactivate endogenous enzymes, recentrifuged $\left(30 \mathrm{~min}, 4^{\circ} \mathrm{C} ; 27,000 \times \mathrm{g}\right)$ in sterile bottles, and stored at $-20^{\circ} \mathrm{C}$. The pasteurization efficacy was evaluated by plating $100 \mu \mathrm{L}$ of saliva onto brain heart infusion (BHI) agar and by observing the absence of bacterial growth after 72 hours. The sterile disks were placed in a sterile 24-well polystyrene cell culture plate containing $500 \mu \mathrm{L}$ of saliva for 4 hours to allow salivary pellicle formation.

2.5. Biofilm Formation Assay. After coating period, saliva was aspirated from each well and replaced with $500 \mu \mathrm{L}$ of BHI broth (double concentrated) and $500 \mu \mathrm{L}$ of saliva. Inocula were prepared by harvesting each standard reference strain cell from BHI agar plates previously inoculated and incubated under microaerophilic conditions for 24 hours (candle jar, $37^{\circ} \mathrm{C}$ ). The bacterial cells were suspended in sterile saline solution, adjusting the turbidity to $\mathrm{OD}_{630} 0.15$ $\left(\sim 10^{6} \mathrm{UFC} / \mathrm{mL}\right)$. Each well was inoculated with $100 \mu \mathrm{L}$ of this inoculum suspension. Plates were then incubated for 16 hours under microaerophilic conditions. Afterwards, the specimens were gently washed in sterile saline solution three times in order to remove unattached cells.

The specimens with remaining attached bacteria were fixed using $0.25 \mathrm{~mL}$ of $2.5 \%$ glutaraldehyde per well for $15 \mathrm{~min}$ and, subsequently, air-dried. The specimens were transferred to clean well plates and were stained with $0.25 \mathrm{~mL}$ of crystal violet for $5 \mathrm{~min}$. Excess stain was rinsed off by placing the microplate under running tap water, and after this it was air-dried. The specimens were transferred to clean tubes, and, in order to resolubilize the dye bound to the adherent cells on specimen surfaces, $0.3 \mathrm{~mL}$ of ethanol was added per well. The supernatant was transferred to a clean 96well microplate, and the absorbance was measured at $570 \mathrm{~nm}$ using an automated 96-well microplate reader.

2.6. Statistical Analysis. The surface characterization was tested using Student's $t$-test. Two-way analysis of variance (ANOVA) was used in order to compare the groups of species within the same group of implant surface topography and to verify possible differences among specimen surfaces within the same species $(\alpha=0.05)$.

\section{Results}

3.1. Surface Characterization of Implants Surfaces Substrata. Scanning electronic microscopy showed that M group exhibited only the grid of machining (Figure 1(a)). On the other 


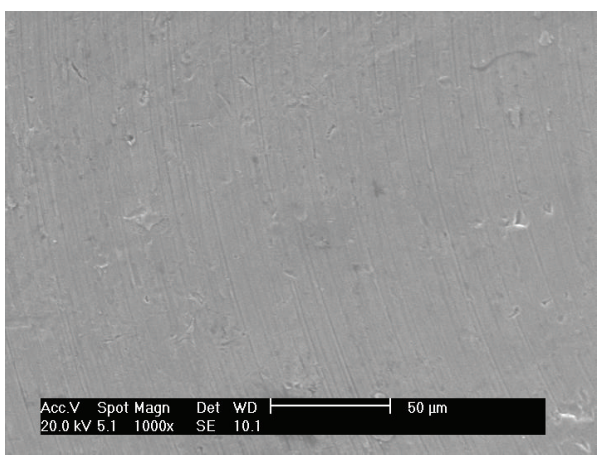

(a)

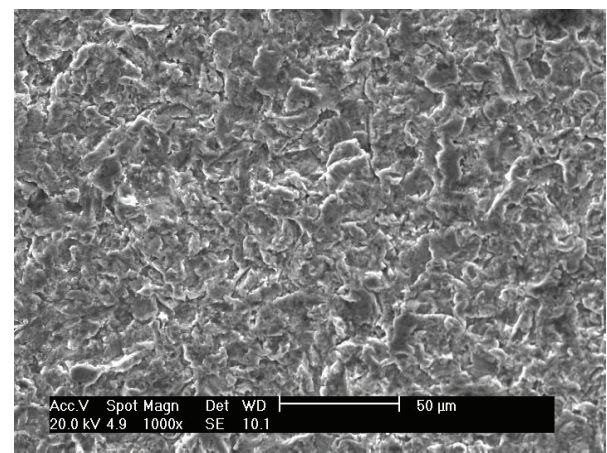

(b)

FIGURE 1: Scanning electron microphotograph of the implant surface topography: (a) as-machined implant surface and (b) sandblasted acidetched surface.

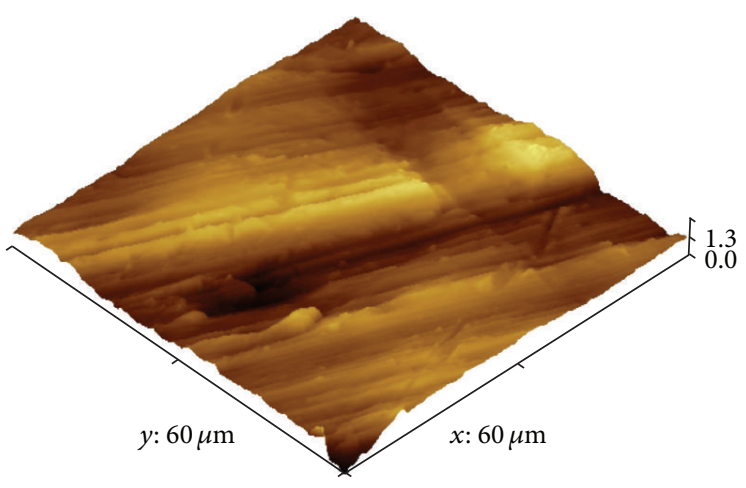

(a)

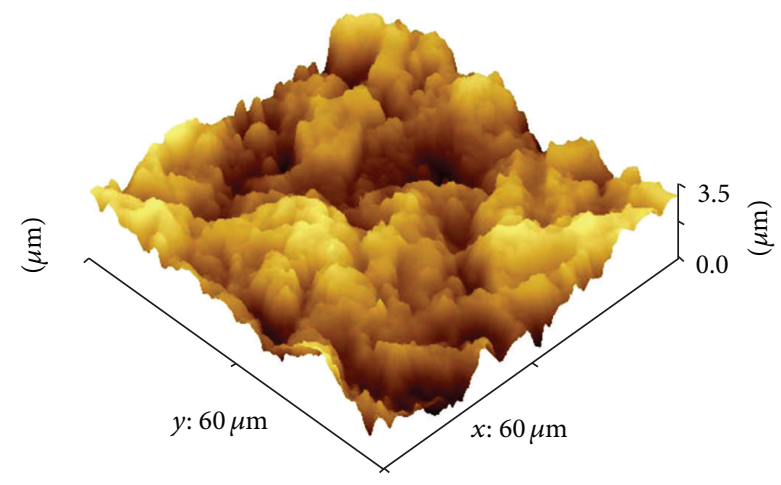

(b)

FIGURE 2: Atomic force microscopy (AFM) of the implant surface topography: (a) as-machined implant surface and (b) sandblasted acidetched surface.

hand, the SAE exhibited peaks and valleys with diverse irregularities (Figure 1(b)).

The surfaces were characterized by atomic force microscopy, which revealed differences between the surfaces $(P<$ $0.0001)$. M showed only the machining grids with peaks of $1.3 \mu \mathrm{m}$ and some regions that were almost flat (Figure 2(a)). The SAE exhibited irregular surfaces with peaks of about $6.5 \mu \mathrm{m}$ (Figure $2(\mathrm{~b})$ ). The roughness values are shown in Table 1.

3.2. In Vitro Determination of Microbial Adhesion. The biofilm forming ability was evaluated and the means of readings are shown in Figure 3. The group mutans streptococci ( $S$. cricetus, S. mutans, and S. sobrinus) exhibited higher levels of biofilm formation and no differences were observed between surfaces analyzed within each species $(P>0.05)$. It was observed that although $S$. cricetus exhibited the highest ability to form biofilm on SAE, among all species, within this species this difference was not significant $(P>0.05)$ between the surfaces analyzed.

S. sanguinis exhibited a similar behavior to form biofilm on both implant surface topographies (Figure 4), and their ability to do so was lower than that of the group mutans streptococci species. The lowest ability was observed for $S$. salivarius.
TABLE 1: Mean \pm standard deviation of the as-machined (MS) and titanium discs blasted with titanium oxide particles and washed with maleic acid solution (SAE) profilometry.

\begin{tabular}{lccc}
\hline $\begin{array}{l}\text { Implant surface } \\
\text { topography* }\end{array}$ & $\mathrm{Ra}(\mu \mathrm{m})$ & $\mathrm{Rq}(\mu \mathrm{m})$ & $\mathrm{Rz}(\mu \mathrm{m})$ \\
\hline As-machined $(\mathrm{M})$ & $0.14 \pm 0.02$ & $0.16 \pm 0.01$ & $1.61 \pm 0.10$ \\
\hline $\begin{array}{l}\text { Sandblasted } \\
\text { acid-etched } \\
\text { surface (SAE) }\end{array}$ & $0.87 \pm 0.14$ & $1.12 \pm 0.18$ & $5.14 \pm 0.69$ \\
\hline
\end{tabular}

${ }^{*}$ Statistically significant between the implant surface topographies (Student's $t$-test $P=0.0001), \mathrm{M}<\mathrm{SAE}$; Ra: arithmetic average of the absolute values of all profile points; Rq: the root-mean-square of the values of all points; Rz: the average value of the absolute heights of the five highest peaks and the depths of the five deepest valleys.

\section{Discussion}

Titanium has been widely used as a component of dental implants since the 1970s. More than the improvements in biomechanical performance, these modifications on implant surfaces lead to other biological responses, such as differences in the protein adsorption profiles $[15,16]$, attachment, cell proliferation and differentiation, and fibrin adhesion [17]. The present study presented the biofilm forming ability of 5 oral streptococci species on two different types of surfaces. 


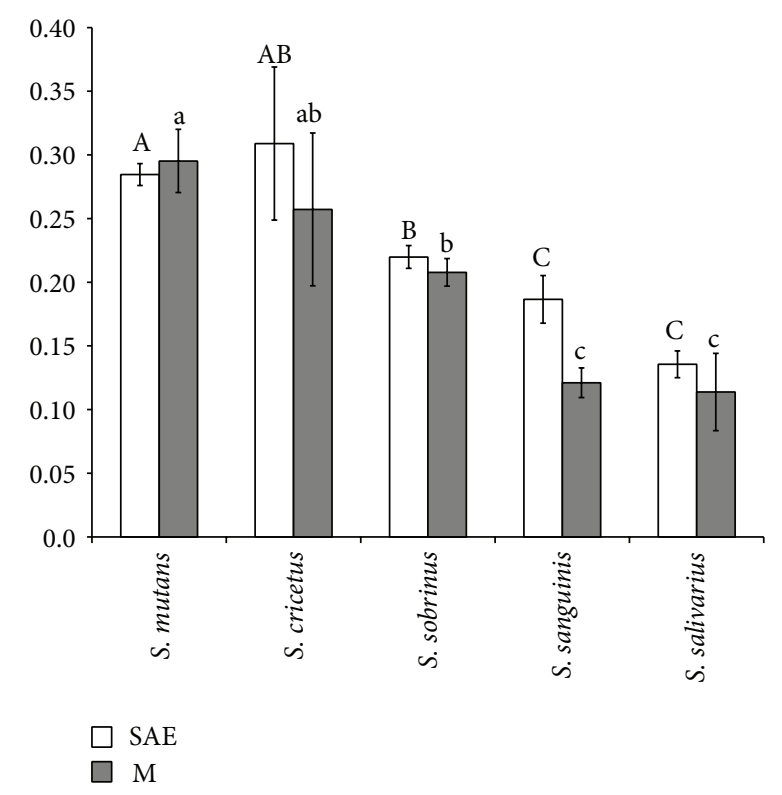

FIgURE 3: Mean \pm standard deviation of the amount of adsorbed dye released after the assay $(P>0.05$; two-way ANOVA). Letters: differences among biofilm accumulated by each species $(P<0.05$; two-way ANOVA/Tukey test). Different letters indicate groups with distinct characteristics. Capital letters compare SAE surfaces, while lower case letters compare M surfaces.

The blasting process with titanium oxide particle (50$100 \mu \mathrm{m})$ and maleic acid solution etching modified substantially the surface, which was indeed confirmed by SEM and AFM. AFM revealed higher density of irregularities on $\mathrm{R}$ surface as well higher peaks. An earlier study [17] detected different profiles of plasma adsorption depending on surface treatment (acid etching only and blasting plus acid etching processes) and attributed this difference mainly to the changes in physical properties, since minor alterations in chemical composition were detected. On the other hand, Li et al. [18] found differences on titanium surfaces after application of different treatments, including chemical changes such as an oxide layer and surface contamination, and these might exert some influence on biocompatibility issues. Recently, it has been shown that nanosurfaces could impair bacterial adsorption, suggesting that further studies must be done to evaluate the role of implant surface topography on bacterial colonization [19].

However, there is an unclear debate about the link between bacterial contamination and peri-implantitis [20, 21]. These papers suggested that peri-implantitis is pathology of bone-to-implant interface and that bacterial contamination is only the associated consequence, not the triggering factor. However, we must point out that, until now, there are now clear and consistent evidences to follow this idea.

In addition, these surface changes might also influence biofilm formation, since the earlier steps of this process are related to contact surface extension, surface free energy, topography, wettability, hydrophobicity, and other surface traits $[17,18,22-26]$.

The results of the present study revealed differences as regards the biofilm forming ability among S. salivarius,
S. cricetus, S. mutans, S. sobrinus, and S. sanguinis. Among them, S. salivarius and $S$. sanguinis exhibited the lowest capacity to form biofilm. Two aspects of biofilm forming ability must be pointed out: the specific traits of each species and surface topographies.

Differences on adhesion to glass surface among mutans streptococci group were already observed [27]. The authors found that $S$. rattus adhered less than the other species ( $S$. sobrinus, S. mutans, and S. cricettus) and attributed these results to different properties of the $S$. rattus surface like negative zeta-potentials. In the present study, three species of mutans streptococci group (S. mutans, S. cricetus, and $S$. sobrinus) were evaluated and although the raw values showed a high capacity of $S$. mutans to accumulate biofilm on titanium surface followed by $S$. cricetus and S. sobrinus, statistical differences were observed only between $S$. mutans and S. sobrinus $(P<0.05)$.

Although roughness seems to promote an increase in the amount of plaque, the biofilm composition did not show substantial changes and the establishment of irreversible attachment in the surface irregularities, where microorganisms are protected against mechanical shear [10]. Despite this, the results of our study demonstrated that biofilm formation does not increase markedly on rougher surfaces.

Oral strains, most of them having high surface free energy, might adhere better to hydrophilic substrata [28]. Differences with regard to surface hydrophobicity could be attributed to the acid etching, which could introduce ${ }^{-} \mathrm{OH}$ groups on the surface, thus modifying its chemical properties [29]. According to this hypothesis, these treatments can originate different surfaces, and, consequently, new patterns of adsorbed substances will be originated, which may offer different profiles of receptors for bacterial colonization.

Another issue concerns virulence traits of each species like tooth colonization mechanisms; S. mutans apparently attach by adhesin and glucan mediated mechanisms, whereas S. sobrinus utilize primarily the latter process [30].

\section{Conclusions}

In conclusion, within the limitations of the study, the present findings showed the following: (a) biofilm formation by oral streptococci might vary according to the species; (b) $S$. salivarius and $S$. sanguinis showed the lowest ability to accumulate biofilm; (c) group mutans streptococci accumulated higher amounts of biofilm; (d) the substratum roughness is not the only issue to be considered with regard to bacterial biofilm formation.

\section{Conflict of Interests}

The authors declare that there is no conflict of interests regarding the publication of this paper.

\section{Authors' Contribution}

Jamil Awad Shibli, Claudia Ota-Tsuzuki, and José Augusto Rodrigues were in charge of the elaboration of the study proposal and the financial support of the study, and they 


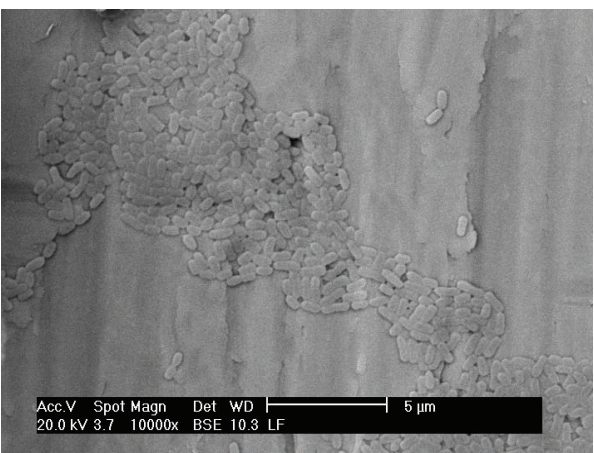

(a)

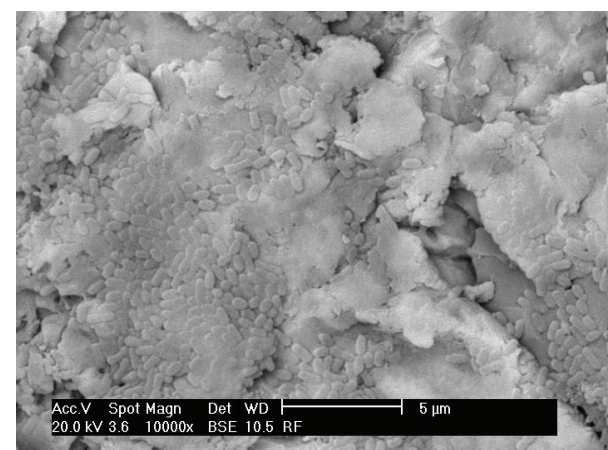

(b)

FIGURE 4: Representative scanning electron microscopy $(\times 10,000)$ in a back scattering mode (BSE) of the Streptococcus sanguinis in (a) asmachined (M) and (b) sandblasted acid-etched (SAE) surface. Note proliferation of the S. sanguinis in the pitches and notches of the SAE surface.

participated in the elaboration of the paper. Luciene C. Figueiredo and Elton G. Zenobio were in charge of the statistical analysis, the implant surface characterization, and the financial support for the study. Pedro Paulo Cardoso Pita, Tatiane Ferreira Miato, Sergio A. Gehrke, Gabriela Giro, and Cristiane Gonçalves were in charge of the saliva collection, laboratory processing, and oral biofilm maintenance and they participated in the elaboration of the paper. Claudia Ota-Tsuzuki and Alessandra Cassoni were in charge of the laboratory processing of the samples and participated in the data analyses and elaboration of the paper.

\section{Acknowledgments}

Dr. Miato received grant from the University of Guarulhos (fellowship PIBIC-UnG). Implacil De Bortoli, Sao Paulo, Brazil, provided the titanium discs.

\section{References}

[1] S. S. Socransky and A. D. Haffajee, "Periodontal microbial ecology," Periodontology 2000, vol. 38, pp. 135-187, 2005.

[2] P. E. Kolenbrander, R. J. Palmer Jr., A. H. Rickard, N. S. Jakubovics, N. I. Chalmers, and P. I. Diaz, "Bacterial interactions and successions during plaque development," Periodontology 2000, vol. 42, no. 1, pp. 47-79, 2006.

[3] J. A. Shibli, L. Melo, D. S. Ferrari, L. C. Figueiredo, M. Faveri, and M. Feres, "Composition of supra- and subgingival biofilm of subjects with healthy and diseased implants," Clinical Oral Implants Research, vol. 19, no. 10, pp. 975-982, 2008.

[4] J. A. Shibli, M. C. Martins, R. F. M. Lotufo, and E. Marcantonio Jr., "Microbiologic and radiographic analysis of ligatureinduced peri-implantitis with different dental implant surfaces," The International Journal of Oral \& Maxillofacial Implants, vol. 18, no. 3, pp. 383-390, 2003.

[5] J. A. Shibli, T. R. C. Vitussi, R. V. Garcia et al., "Implant surface analysis and microbiologic evaluation of failed implants retrieved from smokers," The Journal of Oral Implantology, vol. 33, no. 4, pp. 232-238, 2007.

[6] G. Nakazato, H. Tsuchiya, M. Sato, and M. Yamauchi, "In vivo plaque formation on implant materials," The International
Journal of Oral and Maxillofacial Implants, vol. 4, no. 4, pp. 321326, 1989.

[7] S. Sardin, J.-J. Morrier, G. Benay, and O. Barsotti, "In vitro streptococcal adherence on prosthetic and implant materials. Interactions with physicochemical surface properties," Journal of Oral Rehabilitation, vol. 31, no. 2, pp. 140-148, 2004.

[8] J. A. Shibli, M. C. Martins, L. H. Theodoro, R. F. M. Lotufo, V. G. Garcia, and E. J. Marcantonio, "Lethal photosensitization in microbiological treatment of ligature-induced peri-implantitis: a preliminary study in dogs," Journal of Oral Science, vol. 45, no. 1, pp. 17-23, 2003.

[9] B. Größner-Schreiber, M. Griepentrog, I. Haustein et al., "Plaque formation on surface modified dental implants-an in vitro study," Clinical Oral Implants Research, vol. 12, no. 6, pp. 543-551, 2001.

[10] M. Quirynen, H. C. van der Mei, C. M. Bollen et al., "An in vivo study of the influence of the surface roughness of implants on the microbiology of supra- and subgingival plaque," Journal of Dental Research, vol. 72, no. 9, pp. 1304-1309, 1993.

[11] M. Quirynen, H. C. van der Mei, C. M. Bollen et al., "The influence of surface-free energy on supra- and subgingival plaque microbiology. An in vivo study on implants," Journal of Periodontology, vol. 65, no. 2, pp. 162-167, 1994.

[12] H. K. Kuramitsu, X. He, R. Lux, M. H. Anderson, and W. Shi, "Interspecies interactions within oral microbial communities," Microbiology and Molecular Biology Reviews, vol. 71, no. 4, pp. 653-670, 2007.

[13] A. L. Coykendall, "Classification and identification of the viridans streptococci," Clinical Microbiology Reviews, vol. 2, no. 3, pp. 315-328, 1989.

[14] D. M. D. Ehrenfest, B. S. Kang, G. Sammartino et al., "Guidelines for the publication of articles related to implant surfaces and design from the POSEIDO: a standard for surface characterization," POSEIDO, vol. 1, no. 1, pp. 7-15, 2013.

[15] A. Shibli and D. M. Dohan Ehrenfest, "In dental implant surfaces, NanoWar has begun... but NanoQuest is still at stake!" POSEIDO, vol. 1, no. 3, pp. 131-140, 2013.

[16] J. P. Davidas, "Looking for a new international standard for characterization, classification and identification of surfaces in implantable materials: the long march for the evaluation of dental implant surfaces has just begun," POSEIDO, vol. 2, no. 1, pp. 1-5, 2014. 
[17] M. N. Sela, L. Badihi, G. Rosen, D. Steinberg, and D. Kohavi, "Adsorption of human plasma proteins to modified titanium surfaces," Clinical Oral Implants Research, vol. 18, no. 5, pp. 630638, 2007.

[18] D. Li, S. J. Ferguson, T. Beutler et al., "Biomechanical comparison of the sandblasted and acid-etched and the machined and acid-etched titanium surface for dental implants," Journal of Biomedical Materials Research, vol. 60, no. 2, pp. 325-332, 2002.

[19] E. Elizabeth, G. Baranwal, A. G. Krishnan, D. Menon, and M. Nair, "ZnO nanoparticle incorporated nanostructured metallic titanium for increased mesenchymal stem cell response and antibacterial activity," Nanotechnology, vol. 25, no. 11, Article ID 115101, 2014.

[20] R. Trindade, T. Albrektsson, P. Tengvall, and A. Wennerberg, "Foreign body reaction to biomaterials: on mechanisms for buildup and breakdown of osseointegration," Clinical Implant Dentistry and Related Research, 2014.

[21] T. Albrektsson, C. Dahlin, T. Jemt, L. Sennerby, A. Turri, and A. Wennerberg, "Is marginal bone loss around oral implants the result of a provoked foreign body reaction?" Clinical Implant Dentistry and Related Research, vol. 16, no. 2, pp. 155-165, 2014.

[22] E. M. C. X. Lima, H. Koo, A. M. Vacca Smith, P. L. Rosalen, and A. A. Del Bel Cury, "Adsorption of salivary and serum proteins, and bacterial adherence on titanium and zirconia ceramic surfaces," Clinical Oral Implants Research, vol. 19, no. 8, pp. 780-785, 2008.

[23] K. Mustafa, A. Wennerberg, J. Wroblewski, K. Hultenby, B. S. Lopez, and K. Arvidson, "Determining optimal surface roughness of $\mathrm{TiO}_{2}$ blasted titanium implant material for attachment, proliferation and differentiation of cells derived from human mandibular alveolar bone," Clinical Oral Implants Research, vol. 12, no. 5, pp. 515-525, 2001.

[24] L. le Guéhennec, A. Soueidan, P. Layrolle, and Y. Amouriq, "Surface treatments of titanium dental implants for rapid osseointegration," Dental Materials, vol. 23, no. 7, pp. 844-854, 2007.

[25] W. Teughels, N. Van Assche, I. Sliepen, and M. Quirynen, "Effect of material characteristics and/or surface topography on biofilm development," Clinical Oral Implants Research, vol. 17, no. 2, pp. 68-81, 2006.

[26] A. Leonhardt, J. Olsson, and G. Dahlén, "Bacterial colonization on titanium, hydroxyapatite, and amalgam surfaces in vivo," Journal of Dental Research, vol. 74, no. 9, pp. 1607-1612, 1995.

[27] H. J. Busscher and H. C. van der Mei, "Physico-chemical interactions in initial microbial adhesion and relevance for biofilm formation," Advances in Dental Research, vol. 11, no. 1, pp. 24-32, 1997.

[28] M. M. Fürst, G. E. Salvi, N. P. Lang, and G. R. Persson, "Bacterial colonization immediately after installation on oral titanium implants," Clinical Oral Implants Research, vol. 18, no. 4, pp. 501508, 2007.

[29] A. H. Weerkamp, H. M. Uyen, and H. J. Busscher, "Effect of zeta potential and surface energy on bacterial adhesion to uncoated and saliva-coated human enamel and dentin," Journal of Dental Research, vol. 67, no. 12, pp. 1483-1487, 1988.

[30] H. M. W. Uyen, J. M. Schakenraad, J. Sjollema et al., "Amount and surface structure of albumin adsorbed to solid substrata with different wettabilities in a parallel plate flow cell," Journal of Biomedical Materials Research, vol. 24, no. 12, pp. 1599-1614, 1990. 

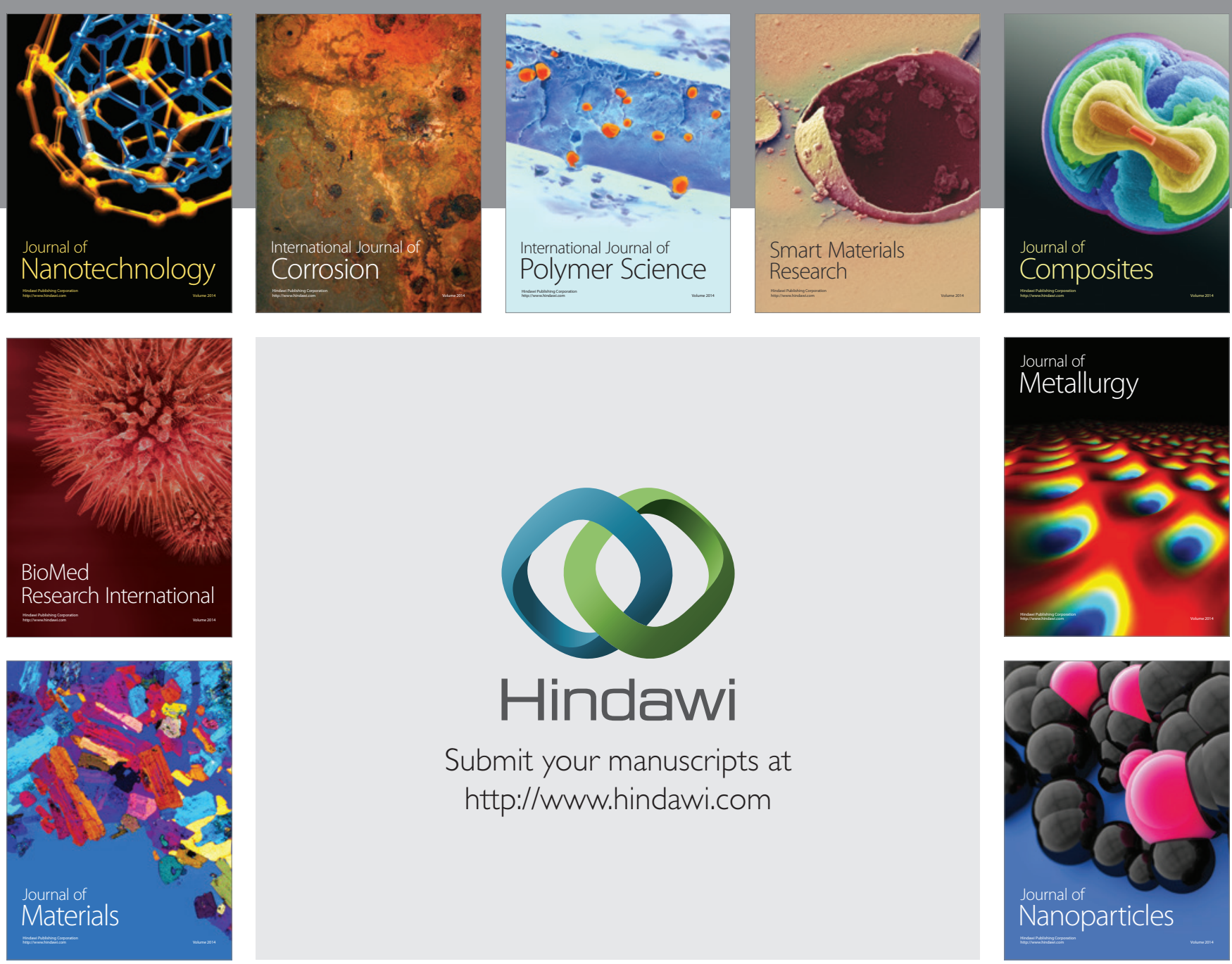

Submit your manuscripts at http://www.hindawi.com
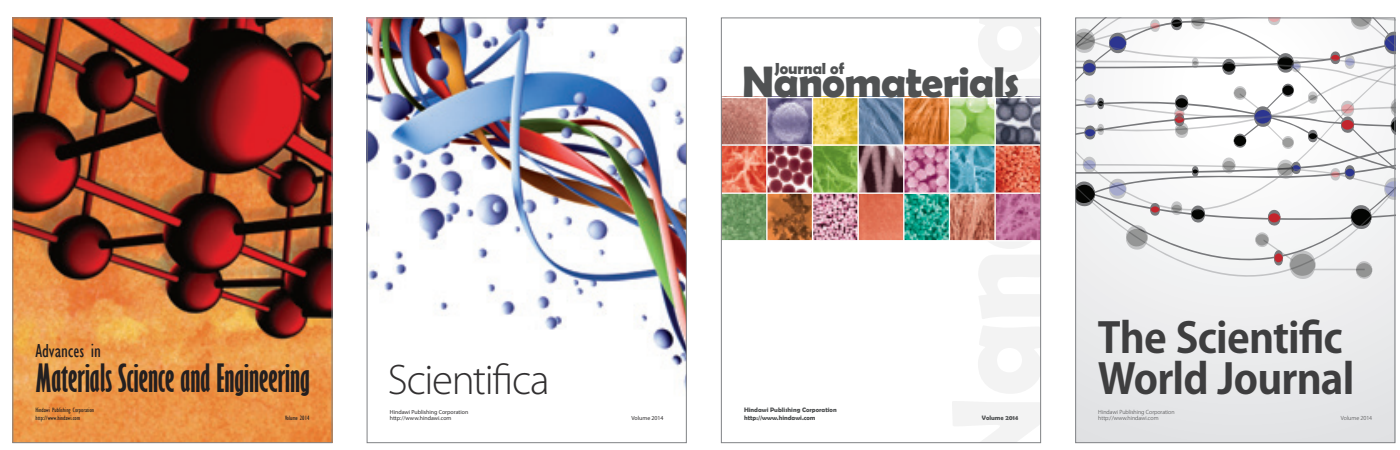

\section{The Scientific World Journal}
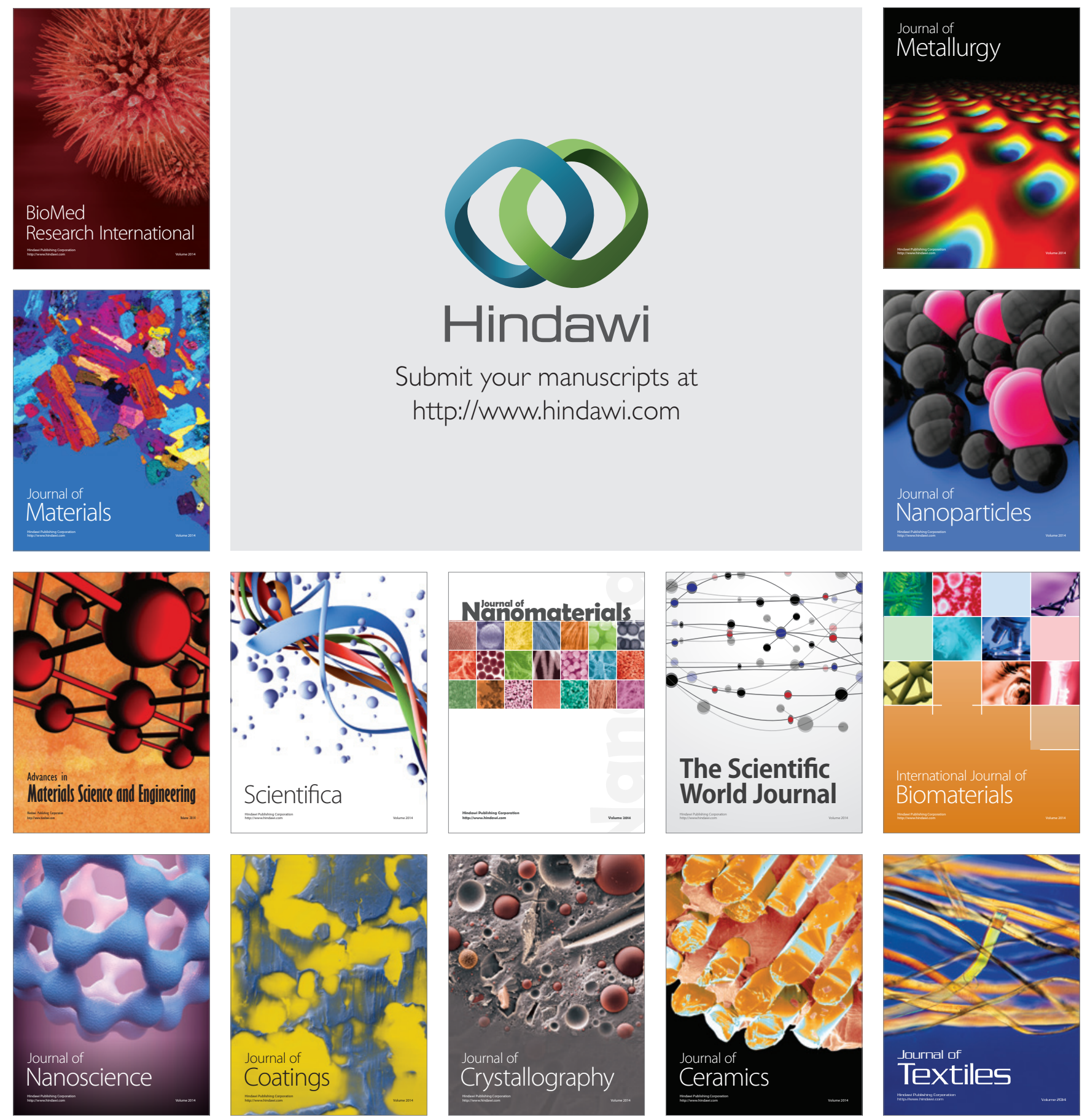